\title{
Kinetic Analytical Method for Determination of Uric Acid in Human Urine using Analyte Pulse Perturbation Technique
}

\author{
Nataša D. Pejić, ,*a Jelena P. Maksimović, ${ }^{b}$ Slavica M. Blagojević, ${ }^{a}$ \\ Slobodan R. Anić, ${ }^{c}$ Željko D. $\breve{C}_{\text {upićc }}^{c}$ and Ljiljana Z. Kolar-Anićc ${ }^{b}$ \\ ${ }^{a}$ Department of Physical Chemistry and Instrumental Methods, Faculty of Pharmacy, \\ University of Belgrade, Vojvode Stepe 450, 11000 Belgrade, Serbia \\ ${ }^{b}$ Faculty of Physical Chemistry, University of Belgrade, Studentski trg 12-16, \\ P.O. Box 137, 11000 Belgrade, Serbia \\ ${ }^{c}$ Department of Catalysis and Chemical Engineering, IHTM, University of Belgrade, \\ Njegoševa 12, 11000 Belgrade, Serbia
}

Novos métodos simples e confiáveis para a determinação de ácido úrico (UA) são propostos e validados. Para a determinação quantitativa de UA, duas matrizes foram usadas: a reação oscilatória de Bray-Liebhafsky (BL) em um estado estacionário de não equilíbrio, estável, próximo ao ponto de bifurcação (método A), e o subsistema não oscilante (mistura de $\mathrm{KIO}_{3}$ e $\mathrm{H}_{2} \mathrm{SO}_{4}$ ), isto é, reação de Dushman (RD) em um estado estacionário (método B). Os métodos propostos são otimizados num reator tanque continuamente agitado (CSTR) e aplicados com excelentes resultados na determinação de UA em amostras de urina humana. A relação linear entre o deslocamento potencial máximo $\Delta \mathrm{E}_{\mathrm{m}}$ e o logaritmo da concentração de $\mathrm{UA}$ (processo $\mathrm{A}$ ), ou entre $\Delta \mathrm{E}_{\mathrm{m}}$ e a concentração UA (processo B) é obtido no intervalo de concentração $2,98 \times 10^{-5}-2,68 \times 10^{-4} \mathrm{~mol} \mathrm{~L}^{-1} \mathrm{e}$ $2,98 \times 10^{-5}-3,58 \times 10^{-4} \mathrm{~mol} \mathrm{~L}^{-1}$, respectivamente. Os métodos têm uma velocidade de processamento de amostra excelente de 30 amostras h $^{-1}$ (método A) e 7 amostras $^{-1}$ (método B) com sensibilidade determinada para ser $1,1 \times 10^{-5} \mathrm{~mol} \mathrm{~L}^{-1}$ (método A) e $8,9 \times 10^{-6} \mathrm{~mol} \mathrm{~L}^{-1}$ (método $\mathrm{B}$ ), e precisão RSD $\leq 3.4 \%$ para ambos os métodos. Alguns aspectos do possível mecanismo de ação de UA nos sistemas de reação oscilante BL e não-oscilante de Duschman, são discutidos em detalhe.

Simple and reliable novel methods for the determination of uric acid (UA) are proposed and validated. For quantitative determination of UA, two matrices were used: the Bray-Liebhafsky (BL) oscillatory reaction in a stable non-equilibrium stationary state close to the bifurcation point (method $\mathrm{A}$ ) as well as, the $\mathrm{BL}$ non-oscillating subsystem (mixture $\mathrm{KIO}_{3}$ and $\mathrm{H}_{2} \mathrm{SO}_{4}$ ), i.e., Dushman reaction (DR) in a steady state (method $\mathrm{B})$. The proposed methods are optimized in a continuously fed well stirred tank reactor (CSTR) and applied with excellent results in the determination of UA in human urine samples. The linear relationship between maximal potential shift $\Delta \mathrm{E}_{\mathrm{m}}$, and both the logarithm of the UA concentration (procedure A) and UA concentration (procedure B) is obtained in the concentration range $2.98 \times 10^{-5}-2.68 \times 10^{-4} \mathrm{~mol} \mathrm{~L}^{-1}$ and $2.98 \times 10^{-5}-3.58 \times 10^{-4} \mathrm{~mol} \mathrm{~L}^{-1}$, respectively. The methods have an excellent sample throughput of 30 samples $^{-1}$ (method A) and $7 \mathrm{samples} \mathrm{h}^{-1}$ (method B) with the sensitivity determined to be $1.1 \times 10^{-5} \mathrm{~mol} \mathrm{~L}^{-1}$ (method A) and $8.9 \times 10^{-6} \mathrm{~mol} \mathrm{~L}^{-1}$ (method B) as well as the precision RSD $\leq 3.4 \%$ for both methods. Some aspects of the possible mechanism of UA action on the BL oscillating and Duschman non-oscillating reaction systems are discussed in detail.

Keywords: uric acid, perturbation technique, Bray-Liebhafsky oscillatory reaction, Dushman reaction, urine

*e-mail: nata@pharmacy.bg.ac.rs 


\section{Introduction}

Uric acid (UA) [7,9-dihydro-1 $H$-purine-2,6,8(3H)trione] is the primary final product of purine metabolism. As a natural antioxidant that exists in human plasma in relatively higher concentration, ${ }^{1}$ it may play a protection role, because it is involved in many pathological changes. ${ }^{2}$

Determination of this very important biological specie is very significant since abnormal levels of UA in the body fluids are symptoms of several diseases ${ }^{3}$ continuous monitoring of UA would be often recommended in many clinical situations. For different purposes, various methods such as spectrophotometry, ${ }^{4}$ fluorimetry, ${ }^{5}$ electroanalysis, ${ }^{6,7}$ high performance liquid chromatography, ${ }^{8}$ capillary electrophoresis, ${ }^{9}$ chemiluminescence method ${ }^{10}$ and other one ${ }^{11,12}$ have been commonly used to determine concentration of UA. One of the major obstacles in determination of UA is the presence of ascorbic acid as interference in the biological samples. To solve this problem, a variety of new electrochemical sensors has been developed; different modified electrodes show excellent sensitivity, good selectivity and antifouling properties. ${ }^{13,14}$ However, rapid methods based on a relatively simple and inexpensive equipment are desirable.

Up to now, there have been a few papers on the determination of UA by kinetic analytical methods, including analytical techniques having the lactic acidacetone- $\mathrm{Br}^{-}-\mathrm{Mn}^{2+}-\mathrm{H}_{2} \mathrm{SO}_{4}$ oscillatory reaction system as matrix. ${ }^{15}$ Generally, kinetic methods based on the ability of the examined substances to change kinetic parameters of chemical reactions, particularly oscillating chemical reactions, have become remarkably important in view of their comparative advantages; oscillating chemical reactions and their extreme sensitivity to external perturbations make these systems, as matrices, particularly interesting for designing kinetic methods of analysis for the determination of different biologically and pharmaceutically important compounds. ${ }^{16-21}$ When the oscillatory reaction is the matrix, two distinct methods have been proposed. The first above-mentioned method ${ }^{19}$ is based on the relationship between the concentrations of analyte and the response of the matrix in the oscillatory state with respect to the main characters of oscillations, such as amplitude, period and others. In the second method ${ }^{16-18}$ based on perturbing the Bray-Liebhafsky (BL) oscillatory reaction as matrix in a stable stationary state in the vicinity of a bifurcation point the relationship between maximal potential displacement $\left(\Delta \mathrm{E}_{\mathrm{m}}\right)$ in the moment of the perturbation and the analyte concentrations would be analyzed. However, using of analyte pulse perturbation (APP) technique in both oscillatory ${ }^{19}$ and stable steady state in vicinity of bifurcation point, ${ }^{16-18}$ the use of the largest Lyapunov exponent ${ }^{22}$ and the high-sensitive oscillating chemical system ${ }^{23}$ make the technique almost perfect and consequently favorable to use it in real routine analysis.

New kinetic methods to the quantitative determination of UA by electrode potential measurements in the BL matrix, ${ }^{24,25}$ and Dushman reaction (DR) matrix,${ }^{26}$ generated in continuously fed well stirred tank reactor (CSTR), ${ }^{27}$ are proposed in this paper. For this purpose, both the BL matrix in a stable steady state near a bifurcation point and DR matrix in a steady state are perturbed with variable amounts of UA, which result in substantial changes in the potentials of the matrices dynamic states that are relevant to the concentration of UA. In particular, the objective was to develop a high-throughput analytical method that should be capable of detecting UA present in human urine samples.

\section{Experimental}

\section{Reagents and preparation of solutions}

The chemicals used were of analytical grade, while deionized water $(\rho=18 \mathrm{M} \Omega \mathrm{cm})$ was used for preparing the solutions. $\mathrm{KIO}_{3}, \mathrm{H}_{2} \mathrm{SO}_{4}$ and $\mathrm{H}_{2} \mathrm{O}_{2}$ were obtained from Merck (Darmstadt, Germany). UA (> 99\%) was obtained from Acros Organics (New Jersey, USA). The laboratory made aqueous sample solutions of UA prepared by appropriate dilution of an initial stock solution obtained by dissolving (at $60{ }^{\circ} \mathrm{C}$ ) $0.006 \mathrm{~g}$ uric acid in $100 \mathrm{~mL}$ deionized water under ultrasonication (Bandelin Sonorex, Germany). Uric acid standard solutions were daily prepared, no more than $3 \mathrm{~h}$ prior to use. All solutions were kept in amber-colored bottles in the dark.

Urine samples were obtained from laboratory co-workers. No pretreatment of urine samples was conducted. All urine samples were diluted 20 times with deionized water before being subjected to potentiometric measurements. The results were compared with those obtained by an earlier proposed kinetic spectrophotometric method. $^{4}$

\section{Apparatus and equipment}

The instrumental equipment used to perturb the matrices included a $50-\mathrm{mL}$ glass CSTR vessel ${ }^{27}$ (Metrohm model 876-20), thermostat (series U8, MLW Freital), a magnetic stirrer (Combimag RET, IKA, Staufen, Germany), a potential measuring system and peristaltic pumps (manual/ RS 232 controlled peristaltic pumps, type 110, Ole Dich, Hvidovre, Denmark). A PC-multilab EH4 16-bit analog- 
to-digital converter (EH4, Serbia) electrochemistry analyzer was directly connected to the reactor through two electrodes, a platinum working electrode (Metrohm model 6.0301.100, Herisau, Switzerland) and a double junction $\mathrm{Ag} / \mathrm{AgCl}$ electrode (Metrohm model 6.0726.100), and used to record the potential changes. It is known ${ }^{28}$ that the Pt electrode may be used for determination of $\mathrm{I}^{-}$in low acidic iodide solutions, which is supported and confirmed in our research. ${ }^{16}$

CSTR and three tanks containing reagent aqueous solutions $\left(\mathrm{H}_{2} \mathrm{O}_{2}, \mathrm{KIO}_{3}\right.$ and $\left.\mathrm{H}_{2} \mathrm{SO}_{4}\right)$ were fitted with a water recirculation jacket connected to a thermostat. Peristaltic pumps controlled the flows (inflow and outflow) of reactants. Viton tubing (Deutch \& Neuman, Berlin, Germany) was used for transporting the solutions of $\mathrm{KIO}_{3}$ and $\mathrm{H}_{2} \mathrm{SO}_{4}$, and Tygon tubing (Ismatec, Glattbrugg, Switzerland) was used for transporting solution of $\mathrm{H}_{2} \mathrm{O}_{2}$ from their tanks to the reaction vessel. These tubes were connected to teflon tubes (Varian, Darmstadt, Germany), and the reagents were introduced to the reaction vessel through them. The volume of the reaction mixture was kept constant at $22.2 \pm 0.2 \mathrm{~mL}$ by removing the surplus volume of the reaction mixture.

The analyte was introduced using micropipettes (Brand, Wertheim, Germany). A $50 \mu \mathrm{L}$ shot is estimated to last about $0.5 \mathrm{~s}$. The intensity of the perturbation corresponds to the injected amount (in $\mathrm{mol} \mathrm{L}^{-1}$ ) of UA standard samples.

The simulated results were performed using the MATLAB program package. The differential equations derived from the model were integrated using the ode $15 \mathrm{~s}$ solver. All numerical simulations were performed with numerical precision of $10^{-16}$.

\section{Procedures for determination of UA}

Quantitative determination of UA was examined in the BL reaction system (start-up procedure A), as well as in BL subsystem (DR), i.e., in binary mixture of the BL reactants: $\mathrm{H}_{2} \mathrm{SO}_{4}+\mathrm{KIO}_{3}$ (start-up procedure B). These procedures were performed in the way that the validity of both preparatory procedure and the used chemicals was confirmed before the flow experiments started. Consequently, in each of different series of experiments, the flow experiments always start at the same already established steady state.

\section{Procedure A}

Thermostated at $56.0 \pm 0.1^{\circ} \mathrm{C}$ and protected from light, the reaction vessel was filled up with the three separate inflows of the reactant solutions, $5.90 \times 10^{-2} \mathrm{~mol} \mathrm{~L}^{-1} \mathrm{KIO}_{3}$, $6.47 \times 10^{-2} \mathrm{~mol} \mathrm{~L}^{-1} \mathrm{H}_{2} \mathrm{SO}_{4}$ and $1.50 \times 10^{-1} \mathrm{~mol} \mathrm{~L}^{-1} \mathrm{H}_{2} \mathrm{O}_{2}$, at a maximum flow rate of $12 \mathrm{~mL} \mathrm{~min}^{-1}$. Under these conditions, within $3.5 \mathrm{~min}$, about twice the volume of the reaction mixture becomes charged. Then, the inflows were stopped, the stirrer was turned on (900 rpm), and the excess of the reaction mixture was sucked out through a U-shaped glass tube in order to achieve an actual reaction mixture volume, $22.2 \pm 0.2 \mathrm{~mL}$. Hence, the reaction commenced under the batch conditions. After two batch oscillations (after about $20 \mathrm{~min}$ ), the inflows were turned on at the required specific flow rate, $2.95 \times 10^{-2} \mathrm{~min}^{-1}$, and the inflow concentration of sulfuric acid was varied at the interval $4.22 \times 10^{-2} \mathrm{~mol} \mathrm{~L}^{-1} \leq\left[\mathrm{H}_{2} \mathrm{SO}_{4}\right]_{0} \leq 9.00 \times 10^{-2} \mathrm{~mol} \mathrm{~L}^{-1}$. In this way, after two batch oscillations obtained under the above-mentioned conditions, in the subsequent routine analysis, the inflow concentration of sulfuric acid was immediately adjusted to the selected operation value $\left(\left[\mathrm{H}_{2} \mathrm{SO}_{4}\right]_{0}=8.02 \times 10^{-2} \mathrm{~mol} \mathrm{~L}^{-1}\right)$. The preparatory procedure took about $50 \mathrm{~min}$. Conditions similar to the $\mathrm{BL}$ reaction for the development of the procedure for the determination of both dynamic states of the BL reaction ${ }^{29}$ and vitamins of $\mathrm{B}$ group ${ }^{18}$ but it should be pointed out that the examined inflow concentrations of $\mathrm{H}_{2} \mathrm{SO}_{4}$ reported here are varied in broader interval from those used in literature. ${ }^{18}$

\section{Procedure B}

This procedure is based upon experiments carried out in acidic iodate solutions and when the inflow concentration of hydrogen peroxide is zero. Thermostated at $56.0 \pm 0.1{ }^{\circ} \mathrm{C}$ and shielded from light, the reaction vessel was filled up by three separate inflows of $5.90 \times 10^{-2} \mathrm{~mol} \mathrm{~L}^{-1} \mathrm{KIO}_{3}$, $6.47 \times 10^{-2} \mathrm{~mol} \mathrm{~L}^{-1} \mathrm{H}_{2} \mathrm{SO}_{4}$ and water, at a maximum flow rate of $12 \mathrm{~mL} \mathrm{~min}^{-1}$. Under these conditions, within $3.5 \mathrm{~min}$, about twice the volume of the reaction mixture became charged. Then, the inflows were stopped, the stirrer was turned on (900 rpm), and the excess of the reaction mixture was sucked out through the $\mathrm{U}$-shaped glass tube to achieve the actual reaction mixture volume, $22.2 \pm 0.2 \mathrm{~mL}$. After about $15 \mathrm{~min}$, the inflows were turned on at the required specific flow rate, $2.95 \times 10^{-2} \mathrm{~min}^{-1}$, and the inflow concentration of sulfuric acid were adjusted to the working value $\left(\left[\mathrm{H}_{2} \mathrm{SO}_{4}\right]_{0}=5.57 \times 10^{-2} \mathrm{~mol} \mathrm{~L}^{-1}\right)$. The preparatory procedure took about $1 \mathrm{~h}$.

\section{Results and Discussion}

For determination of UA, it was chosen the BL oscillating reaction, ${ }^{24,25}$ i.e., the reaction of $\mathrm{H}_{2} \mathrm{O}_{2}$ decomposition catalyzed by $\mathrm{H}^{+}$and $\mathrm{IO}_{3}^{-}$ions was used as the main process. This deceptively simple reaction proceeds through a complex mechanism comprising a series of iodine-containing intermediates such as $\mathrm{I}^{-}, \mathrm{I}_{2}$, 
$\mathrm{HIO}, \mathrm{HIO}_{2}$ and $\mathrm{I}_{2} \mathrm{O} \cdot .^{24,25,30-33}$ In the oscillatory dynamic state during the course of the reaction, periodical changes in the concentration of the intermediates are reflected in cyclic changes in the redox potential. Non-periodicity or even chaos is also possible under specific reaction conditions. ${ }^{29,34}$

A part of the mechanism of the $\mathrm{BL}$ reaction is:

$\mathrm{IO}_{3}^{-}+5 \mathrm{I}^{-}+6 \mathrm{H}^{+} \rightarrow 3 \mathrm{I}_{2}+3 \mathrm{H}_{2} \mathrm{O}$

(DR)

that is the reduction of iodate by iodide in acid solution, known as the Dushman reaction (DR). ${ }^{26}$ Moreover, DR itself is a very important reaction in analytical chemistry and has a crucial role in many interesting systems such as the mentioned $\mathrm{BL}$ oscillating reaction system ${ }^{32,35-37}$ as well as the iodate-arsenous system. ${ }^{38} \mathrm{Hence}$, DR is a part of the highly sensitive BL system, but it is also a potential medium for analytical procedures. Therefore, there is a need to investigate comparative advantages of both $\mathrm{BL}$ and DR reaction systems in analytical evaluation of UA concentration.

\section{Optimization of experimental variables}

Experimental procedure $\mathrm{A}$ ( $\mathrm{BL}$ oscillating reaction system as matrix)

As previous underlined, ${ }^{17,18}$ the experimental conditions for application of the proposed analytical method should be optimized, including the location of the actual bifurcation point in the parameter phase space (bifurcation analysis), the selection of dynamic states that are to be perturbed and the influence of the selected dynamic state on the sensitivity of the matrix system. As previously described, ${ }^{29}$ two bifurcation points were found, the lower bifurcation point for $\left[\mathrm{H}_{2} \mathrm{SO}_{4}\right]_{0}=5.57 \times 10^{-2} \mathrm{~mol} \mathrm{~L}^{-1}$ as well as the higher one for $\left[\mathrm{H}_{2} \mathrm{SO}_{4}\right]_{0}=7.95 \times 10^{-2} \mathrm{~mol} \mathrm{~L}^{-1}$. The bifurcation diagram is shown in Figure 1.

As a rule, in the next step several dynamic states were tested (indicated by arrows in Figure 1) in order to find the maximum response to the analyte, i.e., the optimal injection point. In particular, in the vicinity of the lower bifurcation point the nonequilibrium stationary states that are realized for $\left[\mathrm{H}_{2} \mathrm{SO}_{4}\right]_{0}=4.79 \times 10^{-2}, 5.07 \times 10^{-2}$ and $5.35 \times 10^{-2} \mathrm{~mol} \mathrm{~L}^{-1}$ (region I) was perturbed as well as in vicinity of the higher one for $\left[\mathrm{H}_{2} \mathrm{SO}_{4}\right]_{0}=8.02 \times 10^{-2}$, $8.16 \times 10^{-2}, 8.30 \times 10^{-2}, 8.42 \times 10^{-2}, 8.60 \times 10^{-2}$ and $9.00 \times 10^{-2} \mathrm{~mol} \mathrm{~L}^{-1}$ (region IV). The responses of the system for the perturbations in the just mentioned stable steady states I and IV are different.

When dynamic states characteristic for region IV are realized, typical traces of the BL matrix obtained in the

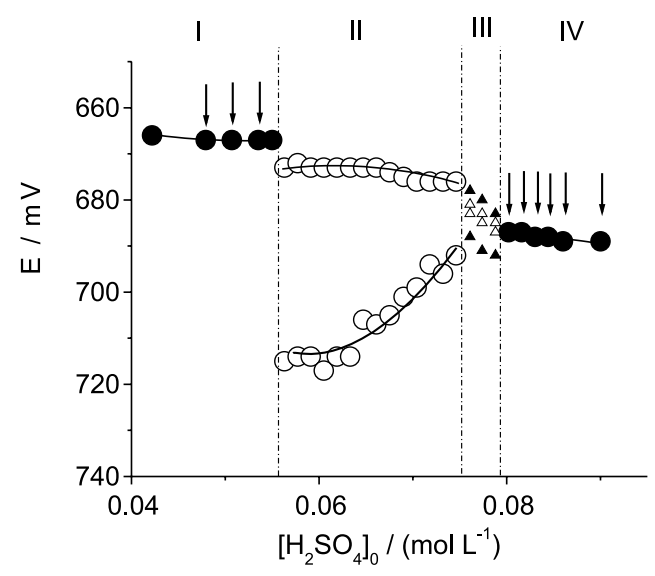

Figure 1. Bifurcation diagram for the BL matrix shows transition from the stable stationary state (solid circles) to the large-amplitude oscillations (open circles) and small amplitude oscillation (triangle) denoting minimal and maximal potential of Pt electrode in an oscillation; dash doted lines show the boundary between different dynamic structures: stable stationary states (I and IV), oscillatory states (II) and aperiodic mixed mode oscillations (III). The perturbed stable nonequilibrium stationary states are indicated by arrows.

absence as well as in the presence of different amounts of perturbing UA are illustrated in Figure 2a. Thus, before perturbation, the system is in a stable stationary state, while its corresponding potential is denoted as $\mathrm{E}_{\mathrm{s}}$. When a trace amount of UA was injected into the BL matrix, both an initial abrupt change in potential and overshoot-decay response were observed. The latter is irreproducible and cannot be used for quantitative determination. Therefore, $E_{p}$ and $E_{s}$ where $E_{p}$ is the minimal value of the potential achieved after applying the perturbation are used for analytical purposes as representative potential values. The response to each UA perturbation was evaluated using maximum potential displacement (analytical signal), $\Delta \mathrm{E}_{\mathrm{m}}=\mathrm{E}_{\mathrm{p}}-\mathrm{E}_{\mathrm{s}}$.

The sensitivity of the BL matrix to the perturbations with UA obtained for inflow concentration $\left[\mathrm{H}_{2} \mathrm{SO}_{4}\right]_{0}=5.07 \times 10^{-2} \mathrm{~mol} \mathrm{~L}^{-1}$ that is in vicinity of lower bifurcation point is illustrated in Figure 3.

In this case (Figure 3), the responses of the matrix system are significantly different with respect to the previous case (Figure 2a). Moreover, an injection of UA $\left(\mathrm{c}_{\mathrm{UA}} \geq 1.61 \times 10^{-3} \mathrm{~mol} \mathrm{~L}^{-1}\right)$ leads to the excitation of a new oscillation followed by a different relaxation route. As a rule,${ }^{29}$ perturbations performed under the conditions where excitability is observed are not appropriate for quantitative determination of $\mathrm{UA}$, when $\Delta \mathrm{E}_{\mathrm{m}}$ was used as analytical signal. On the other hand, both analyzed stable nonequilibrium states that are connected with thw oscillatory region are sensitive to UA, but in different ways. In this sense, some other characteristic dynamic properties of the matrix are likely to be correlated with concentration of UA. The change of the characteristic dynamic property 


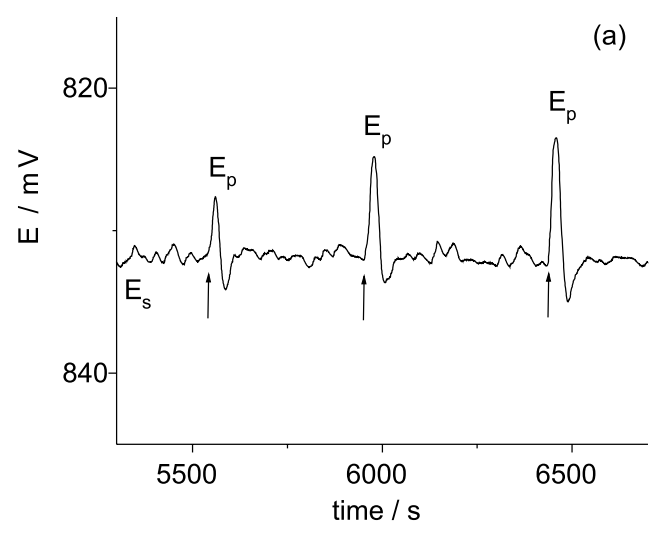

(b)

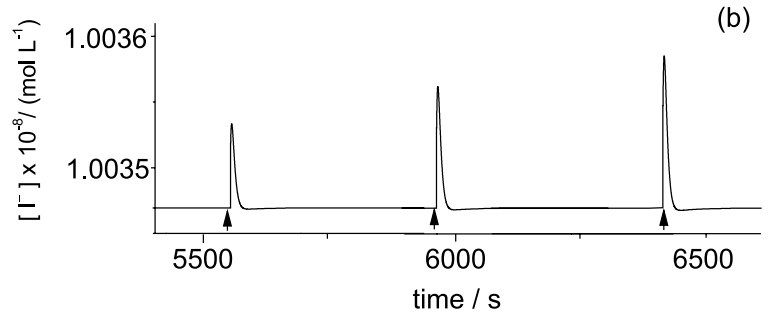

Figure 2. Typical potentiometric responses of BL matrix obtained experimentally (a) and by numerical simulations (b) under experimental conditions A. The inflow concentration of sulfuric acid was $\left[\mathrm{H}_{2} \mathrm{SO}_{4}\right]=8.02 \times 10^{-2} \mathrm{~mol} \mathrm{~L}^{-1}$. The intensity of perturbations are (from left to right): $[\mathrm{UA}]=4.40 \times 10^{-5}, 6.30 \times 10^{-5}$ and $7.96 \times 10^{-5} \mathrm{~mol} \mathrm{~L}^{-1}$. Arrows indicate the moments at which stationary states were perturbed.

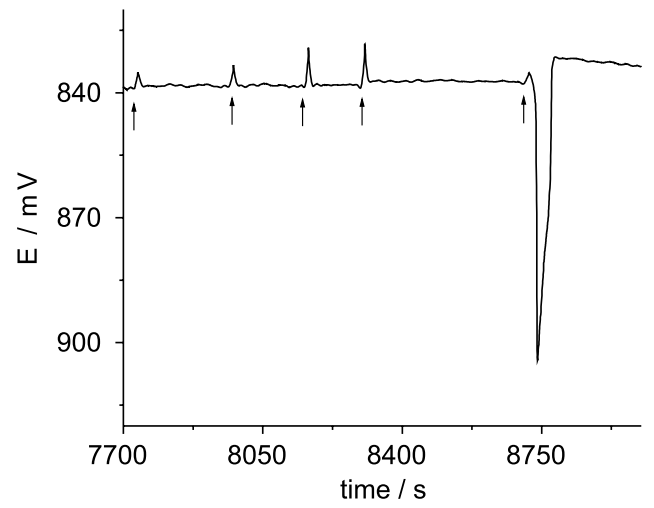

Figure 3. Typical potentiometric responses of the BL matrix obtained after its perturbations in the stable stationary state in vicinity of the lower bifurcation point $\left(\left[\mathrm{H}_{2} \mathrm{SO}_{4}\right]_{0}=5.57 \times 10^{-2} \mathrm{~mol} \mathrm{~L}^{-1}\right)$ with different concentrations of UA. The inflow concentration of sulfuric acid was $5.07 \times 10^{-2} \mathrm{~mol} \mathrm{~L}^{-1}$. Arrows indicate the moment at which (from left to right) $3.58 \times 10^{-4}, 7.15 \times 10^{-4}, 8.95 \times 10^{-4}, 1.43 \times 10^{-3}$ and $1.61 \times 10^{-3} \mathrm{~mol} \mathrm{~L}^{-1}$ of UA was injected, respectively.

in one calibration diagram is not appropriate for analytical purposes.

As can be seen in Figure 4, the maximum response of the considered matrix system to the selected concentration of UA $\left(1.74 \times 10^{-4} \mathrm{~mol} \mathrm{~L}^{-1}\right)$ was obtained for $\left[\mathrm{H}_{2} \mathrm{SO}_{4}\right]_{0}=8.02 \times 10^{-2} \mathrm{~mol} \mathrm{~L}^{-1}$, the case presented in Figure 2a. Consequently, the dynamic state at this acidity was chosen as optimal injection point for UA determination.

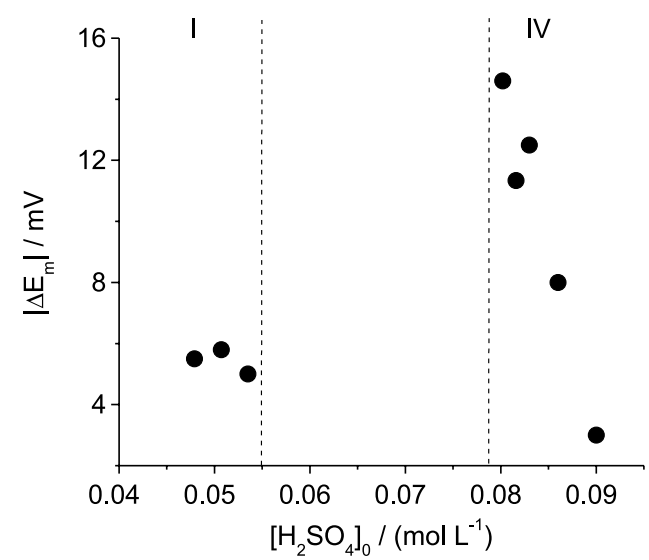

Figure 4. Influence of inflow concentration of sulfuric acid on the absolute value of analytical signal, $\left|\Delta \mathrm{E}_{\mathrm{m}}\right|=\left|\mathrm{E}_{\mathrm{p}}-\mathrm{E}_{\mathrm{s}}\right|$, for the experimental procedure $\mathrm{A}$. The injected concentration of UA is $1.74 \times 10^{-4} \mathrm{~mol} \mathrm{~L}^{-1}$.

\section{Experimental procedure B (DR as matrix)}

Under the CSTR conditions characterized by constant parameters $\left(5.90 \times 10^{-2} \mathrm{~mol} \mathrm{~L}^{-1} \mathrm{KIO}_{3}, 5.57 \times 10^{-2} \mathrm{~mol} \mathrm{~L}^{-1}\right.$ $\mathrm{H}_{2} \mathrm{SO}_{4}$, temperature $56.0{ }^{\circ} \mathrm{C}$ and specific flow rate, $2.95 \times 10^{-2} \mathrm{~min}^{-1}$ ), the effect of concentration of UA was studied; it is found that a variation of its concentration resulted in a variation in $\Delta \mathrm{E}_{\mathrm{m}}$.

The sensitivity of the DR matrix to the perturbations with UA is illustrated in Figure 5a. As can be seen, after introducing the UA, an abrupt change in potential is observed. This sudden response is followed by a relatively slow return to the initial steady state. Here, as in the BL matrix system, analytical signal is defined as maximal potential displacement, $\Delta \mathrm{E}_{\mathrm{m}}=\mathrm{E}_{\mathrm{p}}-\mathrm{E}_{\mathrm{s}}$.

\section{Approach to the determination of UA}

Typical response curves, obtained after both BL oscillating reaction (experimental procedure A) and DR (experimental procedure B) perturbed by additions of UA, are given in Figures 2a and 5a, respectively. A good linear relationship between the $\Delta \mathrm{E}_{\mathrm{m}}$ and both the logarithm of the UA concentration (procedure A) and UA concentration (procedure B) were found. In accordance with ICH guidelines, ${ }^{39}$ linearity, precision, limit of detection (LOD) and limit of quantification (LOQ) were analyzed. Table 1 summarizes the figures of merit of calibration graphs.

For both experimental procedures, the calibration curves exhibited excellent linear behavior over concentration ranges of about one order of magnitude with limits of detection of $1.1 \times 10^{-5} \mathrm{~mol} \mathrm{~L}^{-1}$ (procedure A) and $8.9 \times 10^{-6} \mathrm{~mol} \mathrm{~L}^{-1}$ (procedure $\mathrm{B}$ ), as well as with instrumental sensitivities of $20.8 \mathrm{mV} \mathrm{decade}^{-1}$ (procedure $\mathrm{A}$ ) and $1.8 \times 10^{5} \mathrm{mV}$ decade $^{-1}$ (procedure $\mathrm{B}$ ). The average relative standard deviations $\mathrm{s}^{40}$ (RSD) are $3.4 \%$ (procedure A) and 2.9\% (procedure B), 

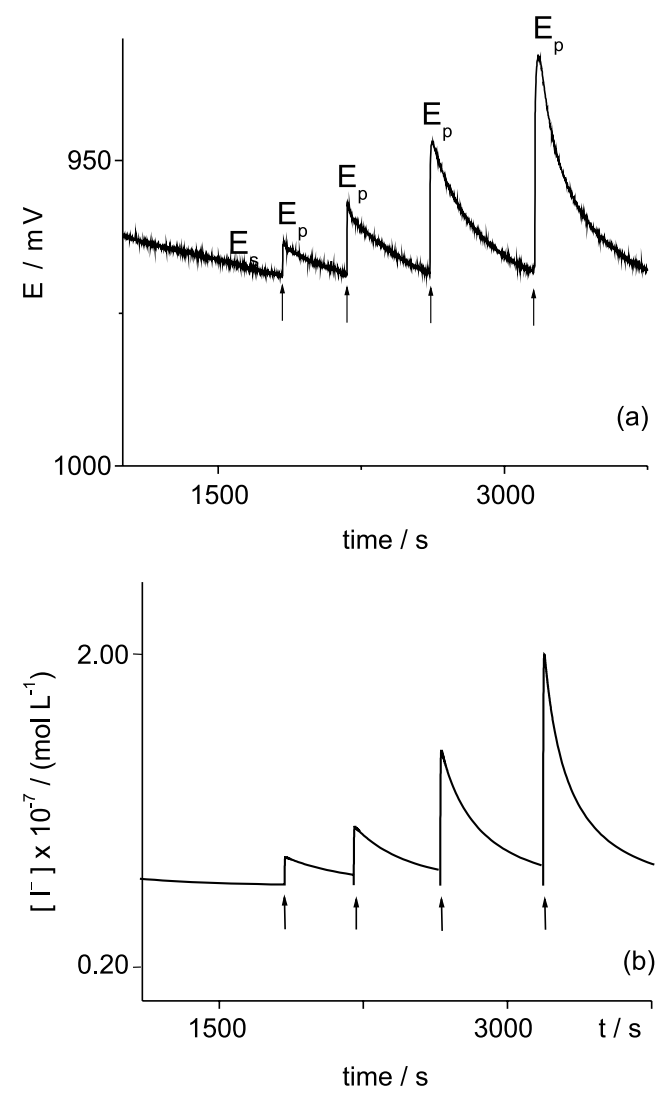

Figure 5. The responses of the DR matrix obtained experimentally (a) and by numerical simulations (b) under experimental conditions B after its perturbations with different concentrations of UA. The inflow concentration of sulfuric acid was $5.57 \times 10^{-2} \mathrm{~mol} \mathrm{~L}^{-1}$. Arrows indicate the moment at which (from left to right) $2.98 \times 10^{-5}, 5.96 \times 10^{-5}, 1.19 \times 10^{-4}$ and $1.79 \times 10^{-4} \mathrm{~mol} \mathrm{~L}^{-1}$ of UA was injected, respectively.

which provide acceptable reproducibility for analysis of a real sample.

In summary, both experimental procedures perform well in determination of UA; however, for procedure A, the method is characterized by a much higher sample throughput (30 samples per hour), although this method has some lower analytical sensitivity (assessed as LOD) related to method B. Also, the method based on perturbation DR matrix (procedure B) is characterized by higher instrumental sensitivity (the slope obtained from regression curve) and method precision when compared with the method based on the perturbation the BL matrix. Also, the advantage of perturbing DR matrix will be well appreciated by investigators with a little, or no-experience with oscillatory reaction system. Here, it is not necessary to determine the bifurcation point and, any change in the dynamic pattern following perturbation is easily observable and unmistakably recognized. On the other hand, the estimated time for a full analysis depends on the matrix system relaxation rate to the same, or slightly different initial steady state, after perturbation with UA. The time required may be shortened by using BL oscillating reaction as matrix, i.e., method A. In addition, if the proposed methods are compared with the method based on perturbations of the lactic acid-acetone- $\mathrm{BrO}_{3}^{-}-\mathrm{Mn}^{2+}-\mathrm{H}_{2} \mathrm{SO}_{4}$ oscillating reaction, ${ }^{15}$ both precision and sample throughput are higher while the time required for a full analysis is considerably shortened than for the latter method.

\section{Interference effect}

The effect of possible interfering substances were studied by perturbing the matrices with solutions containing a fixed amount of standard solutions of UA $\left(1.79 \times 10^{-4} \mathrm{~mol} \mathrm{~L}^{-1}\right)$ and different amounts of various interfering species (different kinds of compounds and inorganic elemental ions known to exist in urines). It was considered that some species did not influence the determination of UA when they affected the analytical signal by less than $\pm 5 \%$. The species examined were found to interfere above the tolerable ratios (TR) (molar concentration of interferent to the molar concentration of UA), given in Table 2 (procedure A), while the values obtained by using procedure $\mathrm{B}$ are given in square brackets.

It should be noted the strong interference of glucose and sucrose (Table 2). These species strongly affect the determination in the DR matrix probably because they may react with $\mathrm{IO}_{3}^{-}$to give off $\mathrm{I}^{-}$, similar to the way they affect in the Belousov-Zhabotinsky type reaction. ${ }^{41}$ The species $\mathrm{I}^{-}$also shows significant interference because it is a crucial intermediate in both matrices as well as thiamine which can react with this anion. ${ }^{18} \mathrm{At}$ the end, $\mathrm{CaCO}_{3}$ shows

Table 1. Analytical figures of merit for the determination of uric acid

\begin{tabular}{|c|c|c|c|c|c|c|c|}
\hline $\begin{array}{l}\text { Experimental } \\
\text { procedure } \\
\text { (matrix) }\end{array}$ & $\begin{array}{l}\text { Linear range / } \\
\left(\mathrm{mol} \mathrm{L}^{-1}\right)\end{array}$ & $\begin{array}{l}\text { Regression } \\
\text { equation }^{\mathrm{a}}\end{array}$ & $\mathrm{r}^{\mathrm{b}}$ & $\mathrm{RSD}^{\mathrm{c}} / \%$ & $\begin{array}{l}\mathrm{LOD}^{\mathrm{d} /} \\
\left(\mathrm{mol} \mathrm{L}^{-1}\right)\end{array}$ & $\begin{array}{l}\mathrm{LOQ}^{\mathrm{e}} / \\
\left(\mathrm{mol} \mathrm{L}^{-1}\right)\end{array}$ & $\begin{array}{c}\mathrm{ST}^{\mathrm{f}} / \\
\left(\text { samples h}^{-1}\right)\end{array}$ \\
\hline $\mathrm{A}(\mathrm{BL})$ & $2.98 \times 10^{-5}-2.68 \times 10^{-4}$ & $Y=-96.2-20.8 \log X$ & 0.9977 & 3.4 & $1.1 \times 10^{-5}$ & $3.2 \times 10^{-5}$ & 30 \\
\hline $\mathrm{B}(\mathrm{DR})$ & $2.98 \times 10^{-5}-3.58 \times 10^{-4}$ & $\mathrm{Y}=-1.1-1.8 \times 10^{5} \mathrm{X}$ & 0.9990 & 2.9 & $8.9 \times 10^{-6}$ & $2.9 \times 10^{-5}$ & 7 \\
\hline
\end{tabular}

${ }^{\mathrm{a}} \mathrm{Y}$, maximal potential shift and $\mathrm{X}$, analyte injected concentration; ${ }^{\mathrm{b}}$ correlation coefficient; ${ }^{\mathrm{c}}$ average relative standard deviations obtained from three determinations of $1.79 \times 10^{-5} \mathrm{~mol} \mathrm{~L}^{-1}$ of UA; ${ }^{\text {dlimit }}$ of detection established at a signal-to-noise ratio of 3 ; ${ }^{\text {elimit }}$ of quantification established at a signal-to-noise ratio of $10 ;{ }^{\mathrm{f}}$ sample throughput is defined as a time needed for the system recovery after each perturbation; RSD: relative standard deviation. 
Table 2. Tolerable concentration of some interfering species in BL and $[\mathrm{DR}]^{\mathrm{b}}$ matrix with respect to $1.79 \times 10^{-4} \mathrm{~mol} \mathrm{~L}^{-1}$ uric acid

\begin{tabular}{lc}
\hline Interfering species & $\begin{array}{c}\text { Tolerable ratio } \\
\text { [interfering species] / [UA] }\end{array}$ \\
\hline Ascorbic acid & $50[0.3]$ \\
Glucose & $>30^{\mathrm{a}}[0.01]$ \\
Sucrose & $>30^{\mathrm{a}}[0.02]$ \\
$\mathrm{Zn}^{2+}$ & $20[3]$ \\
$\mathrm{Ca}^{2+}$ & $20[0.1]$ \\
$\mathrm{Al}^{3+}$ & $20[5]$ \\
$\mathrm{Paracetamol}^{2+}$ & $11[11]$ \\
$\mathrm{HIO}_{3}$ & $10[16]$ \\
$\mathrm{Carbamide}^{2}$ & $10[1]$ \\
$\mathrm{Cl}^{-}$ & $5[5]$ \\
$\mathrm{Mg}^{2+}$ & $2[0.5]$ \\
$\mathrm{Cu}^{2+}$ & $2[10]$ \\
$\mathrm{IO}_{4}^{-}$ & $2[1]$ \\
$\mathrm{Thiamine}^{-}$ & $0.5[0.05]$ \\
$\mathrm{I}^{-}$ & $0.2[0.07]$ \\
$\mathrm{CaCO}_{3}$ & $0.2[0.1]$ \\
\hline
\end{tabular}

${ }^{a}$ Maximum ratio tested; ${ }^{b}$ in square brackets is tolerable ratio obtained by using a method employing the experimental procedure B.

a higher degree of interference probably because UA may be subject to a dissociation process in its presence. ${ }^{42}$ For the other examined interferents (Table 2), generally, when DR is used as matrix, the reducing characteristic of ions and species often have a strong effect on the extent to which the analytes tolerate them. More reductive ions and species, such as $\mathrm{Ca}^{2+}$ and ascorbic acid, interfere more in the UA determination, whereas in the case of BL matrix those influences are vice versa.

\section{Application to real samples}

In order to evaluate the usefulness of those developed methods (A and B), UA was determined in real human urine samples under the optimized conditions. Urine samples were taken from one healthy woman aged 29. The $2.0 \mathrm{~mL}$ of urine sample was diluted to $50.0 \mathrm{~mL}$ in volumetric flask with deionized water. Perturbations of the matrixes (BL reaction and DR) were performed with $50 \mu \mathrm{L}$ of the sample solution. The obtained responses of the used matrixes are shown in Figures 6a and 6b.

The average concentrations of UA in urine were calculated from five replicate measurements of the two independent samples from the same person (Table 3). The average recovery values (RCV), 96.0\% (method A) and $106.7 \%$ (method B), indicate that no matter what limited selectivity (Table 2), the methods developed are free from any interference, and provide accurate results; those methods can be considered to be applicable to real analysis of UA contents in urines. The UA values in the same urine samples were also determined by a kinetic-spectrophotometric method ${ }^{4}$ in order to prove the reliability of the proposed methods. As listed in Table 3, the obtained results correspond to those obtained by the reference method (averages RCV were $98.5 \%$ (method A) and $105.1 \%($ method $B))$.
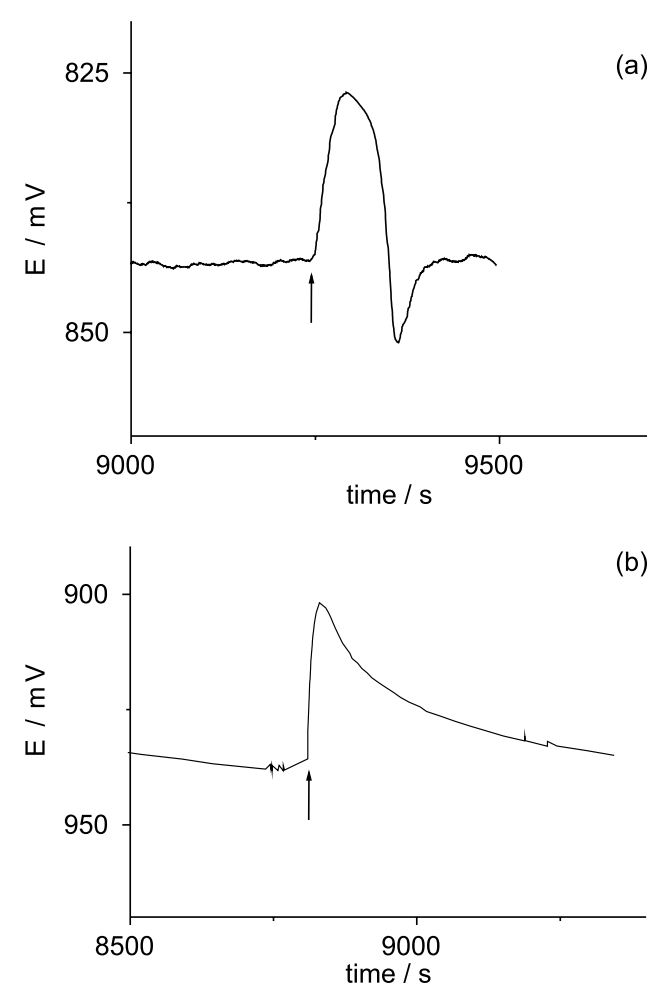

Figure 6. Typical response curves obtained after perturbing both, BL matrix (a) and DR matrix (b) by addition of human urine. Arrows indicate the moment at which urine samples were injected.

Table 3. Determination of uric acid in human urine samples

\begin{tabular}{lccc}
\hline Method & $\begin{array}{c}\text { Urine } \\
\text { sample }\end{array}$ & $\begin{array}{c}\mathrm{UA} \mathrm{found}^{\mathrm{a}} / \\
\left(\mathrm{mol} \mathrm{L}^{-1}\right)\end{array}$ & $\mathrm{RCV}^{\mathrm{b}} \pm \mathrm{RSD} / \%$ \\
\hline $\mathrm{A}$ & 1 & $3.58 \times 10^{-3}$ & $94.5 \pm 3.1$ \\
& 2 & $3.79 \times 10^{-3}$ & $97.5 \pm 4.2$ \\
$\mathrm{~B}$ & 1 & $4.30 \times 10^{-3}$ & $108.3 \pm 2.0$ \\
& 2 & $4.40 \times 10^{-3}$ & $105.1 \pm 3.0$ \\
Reference method $^{4}$ & 1 & $4.00 \times 10^{-3}$ & $103.6 \pm 1.7$ \\
& 2 & $4.09 \times 10^{-3}$ & $102.1 \pm 0.9$ \\
\hline
\end{tabular}

${ }^{\mathrm{a}}$ Mean value of six determinations $(\mathrm{n}=5)$; ${ }^{\mathrm{b}}$ performed as accurate addition of $1.0 \times 10^{-4} \mathrm{~mol} \mathrm{~L}^{-1}$ uric acid to the real samples.

\section{Interaction of UA with both $\mathrm{BL}$ matrix and DR matrix}

In order to propose the nature of the interaction of UA with BL matrix, a well known and thoroughly tested ${ }^{31,43}$ kinetic scheme was used that has already been used as a 
basic form for mathematical modeling of the interactions between BL matrix and some analytes. ${ }^{17}$ The possible mechanism of the UA interaction with non-oscillating DR matrix was tested on a kinetic scheme that was suggested by Agreda et al. ${ }^{44}$ and which expressed the kinetic complexity of the Dushman reaction. ${ }^{45,46}$

The uric acid $\left(\mathrm{C}_{5} \mathrm{H}_{4} \mathrm{~N}_{4} \mathrm{O}_{3}\right)$ can be oxidized with $\mathrm{HIO}_{3}$ and $\mathrm{I}_{2}{ }^{47,48}$ under acidic condition through a mechanism in which the most characteristic products are alloxan $\left(\mathrm{C}_{4} \mathrm{O}_{4} \mathrm{~N}_{2} \mathrm{H}_{2}\right)$ and urea $\left(\mathrm{CON}_{2} \mathrm{H}_{4}\right)$. On the other hand, based on the recorded strong potentiometric response to small amounts of UA injection in DR, it was suggested the UA oxidation occurs through interaction with hypoiodous acid, as a crucial step in which the most characteristic products are alloxan and urea. With the aim to explain a possible mechanism for the perturbation effect of UA on the matrices, three possible interactions were considered between UA and both BL and DR, and therefore both model mechanisms of these matrices were extended, with each of the individual proposed reactions 1, 2 and 3:

$$
\begin{aligned}
& \mathrm{C}_{5} \mathrm{H}_{4} \mathrm{~N}_{4} \mathrm{O}_{3}+\mathrm{H}^{+}+\mathrm{IO}_{3}^{-}+\mathrm{H}_{2} \mathrm{O} \rightarrow \mathrm{C}_{4} \mathrm{O}_{4} \mathrm{~N}_{2} \mathrm{H}_{2}+\mathrm{CON}_{2} \mathrm{H}_{4}+\mathrm{HIO}_{2}(1) \\
& \mathrm{C}_{5} \mathrm{H}_{4} \mathrm{~N}_{4} \mathrm{O}_{3}+\mathrm{I}_{2}+2 \mathrm{H}_{2} \mathrm{O} \rightarrow \mathrm{C}_{4} \mathrm{O}_{4} \mathrm{~N}_{2} \mathrm{H}_{2}+\mathrm{CON}_{2} \mathrm{H}_{4}+2 \mathrm{I}^{-}+2 \mathrm{H}^{+} \text {(2) } \\
& \mathrm{C}_{5} \mathrm{H}_{4} \mathrm{~N}_{4} \mathrm{O}_{3}+\mathrm{HIO}+\mathrm{H}_{2} \mathrm{O} \rightarrow \mathrm{C}_{4} \mathrm{O}_{4} \mathrm{~N}_{2} \mathrm{H}_{2}+\mathrm{CON}_{2} \mathrm{H}_{4}+\mathrm{I}^{-}+\mathrm{H}^{+}
\end{aligned}
$$

The validity of the extended models was tested by numerical simulations in the same way as described in the literature. ${ }^{17}$ A perturbation in the numerical simulation is performed by instantaneous changing of the concentration of UA during the course of integration of the kinetic equations. The initial concentrations of the external species and flow rate were the same as in experimental procedures A and B.

The rate constants for both BL and DR models reactions were taken from the literature. ${ }^{32,43,44}$ The rate constant for additional reactions ( 2 and 3 ) are estimated in such a way that the rates of these reactions are comparable with the rates of other reactions involving iodine and hypoiodous acid ${ }^{49}$ the rate constant of reaction 1 is estimated through a computer simulation procedure.

The results of numerical simulation for temporal traces upon UA injections, obtained when the reaction 1 or 2 were introduced in both BL model and DR model, were not in a good quantitative agreement with experimental results. The simulated forms of the signal profiles, for all examined concentrations of UA, are in huge discordance with typical response curves experimentally obtained. The relaxation time obtained after perturbing the stationary state in both, BL and DR reaction, by addition of UA, was not in accordance with the experiment as well.
Numerically simulated temporal traces upon UA injections in case when the model of $\mathrm{BL}$ reaction is extended with reaction $3,\left(\mathrm{k}_{3}=1.00 \times 10^{6} \mathrm{dm}^{3} \mathrm{~mol}^{-1} \mathrm{~min}^{-1}\right)$, are shown in Figure 2b. The quantitative measure that characterizes the effect of different UA perturbation strengths on the stable stationary state in BL matrix is the $\Delta \mathrm{E}$ that corresponds to the change of logarithm $\mathrm{I}^{-}$concentration caused by injection of UA in BL matrix. Under the above experimental conditions (procedure A), a plot of the $\Delta \mathrm{E}$ against the logarithm of injected UA concentrations is linear. The obtained linear concentration range and regression equation are $2.98 \times 10^{-5}-2.98 \times 10^{-4} \mathrm{~mol} \mathrm{~L}^{-1}$ and $\mathrm{Y}=-94.7-21.0 \log \mathrm{X}(\mathrm{R}=0.9866)$, respectively. The obtained results resemble experimental ones in a most satisfying level (Table 1).

Numerically simulated temporal traces upon UA injections in cases when model of DR was extended with reaction $3\left(\mathrm{k}_{3}=6.00 \times 10^{7} \mathrm{dm}^{3} \mathrm{~mol}^{-1} \mathrm{~min}^{-1}\right)$, are shown in Figure $5 \mathrm{~b}$. The numerically simulated forms of signal profiles obtained before and after perturbation of the DR matrix by the UA are in excellent agreement with experimentally obtained results. Under the optimal conditions for experimental procedure $\mathrm{B}$, a plot of the $\Delta \mathrm{E}$ against injected UA concentrations is linear. The obtained linear concentration range is $2.98 \times 10^{-5}-3.58 \times 10^{-4} \mathrm{~mol} \mathrm{~L}^{-1}$ and regression equation $\mathrm{Y}=-4.3-1.7 \times 10^{5} \mathrm{X}(\mathrm{R}=0.9948)$. Once again, the obtained results resemble the experimental ones (Table 1).

In summary, for both investigated interactions of UA with the BL and DR matrix, it is obtained a good qualitative and quantitative agreement between experiments and simulated results: the form of the signal profile and the relaxation times are virtually identical, and the linearity ranges of the obtained regression equation are very well comparable with experimentally determined ones. Having in mind that the simulated results obtained by including the reaction 3 in the reaction mechanisms for both, Bray-Liebhafsky oscillatory reaction and Dushman non-oscillatory reaction, successfully reproduce the experimental results, we suggested, as a first approximation, that UA oxidation through interaction with HIO is crucial and the rate-determining step in a possible model of the mechanism of the interaction between UA and the BL matrix and DR matrix reaction systems.

\section{Conclusions}

The results demonstrate the suitability of the use of the BL oscillatory reaction matrix and DR matrix for the determination of UA in both, bulk solution and human urine samples. Compared with other analytical equipments, 
the set-up used in the proposed methods are simple and cheap; they operate without any derivatization reaction and show good analytical features. On the other hand, the main limitations of the proposed methods are relatively longer time required for a full analysis as well as a strong interference with some compounds such as thiamine, iodide and calcium carbonate (methods A and B) as well as ascorbic acid, glucose and sucrose (method B). Therefore, it may be applicable for UA determination in samples that contain sufficiently low concentrations of these substances. Wherever, both methods are accurate and precise, and they are very appropriate for routine analysis of UA in human urines.

\section{Acknowledgments}

The present investigations were partially supported by The Ministry of Sciences and Education of Serbia, under projects 172015 and 45001 .

\section{References}

1. Menon, R. K.; Mikhailidis, D. P.; Bell, J. L.; Kernoff, P. B.; Dandona, V.; Clin. Chem. 1986, 32, 1557.

2. Forman, J. P.; Choi, H.; Curhan, G. C.; J. Am. Soc. Nephrol. 2007, 18, 287.

3. Kang, D. H.; Nakagawa, T.; Feng, L. L.; Watanable, S.; Han, L.; Mazzali, M.; Truong, L.; Harris, R.; Johnson, R. J.; J. Am. Soc. Nephrol. 2002, 13, 2888.

4. Dutt, V. S. E.; Mottola, H. A.; Anal. Chem. 1974, 46, 1777.

5. Galbán, J.; Andreu, Y.; Almenara, M. J.; de Marcos, S.; Castillo, J. R.; Talanta 2001, 54, 847.

6. Lakshmi, D.; Whitcombe, M. J.; Davis, F.; Sharma, P. S.; Prased, B. B.; Electroanalysis 2011, 23, 305.

7. dos Reis, A. P.; Tarley, C. R. T.; Kubota, L. T.; J. Braz. Chem. Soc. 2008, 19, 1567.

8. George, S. K.; Dipu, M. T.; Mehra, U. R.; Singh, P.; Verma, A. K.; Ramgaokar, J. S.; J. Chromatogr., B: Anal. Technol. Biomed. Life Sci. 2006, 832, 134.

9. Barbas, C.; Vallejo, M.; García, A.; Barlow, D.; Hanna-Brown, M.; J. Pharm. Biomed. Anal. 2008, 47, 388.

10. Yang, C.; Zhang, Z.; Talanta 2010, 81, 477.

11. Seki, T.; Yamai, K.; Orita, Y.; Moriguchi, S.; Shinoda, A.; J. Chromatogr., A 1996, 730, 139.

12. Zuo, Y.; Yang, Y.; Zhu, Z.; He, W.; Aydin, Z.; Talanta 2011, 83, 1707.

13. Niu, L.; Lian, K.; Kang, W.; Li, S.; J. Braz. Chem. Soc. 2011 , 22, 204.

14. Miah, Md. R.; Masud, J.; Ohsaka, T.; Electrochim. Acta 2008, $54,316$.

15. Wang, J.; Yang, S.; Cai, R.; Lin, Y.; Liu, Y.; Talanta 2005, 65, 799.
16. Vukojević, V.; Pejić, N.; Stanisavljev, D.; Anić, S.; Kolar-Anić, Lj.; Analyst 1999, 124, 147.

17. Pejić, N.; Blagojević, S.; Anić, S.; Vukojević, V.; Mijatović, M.; Ćirić, J.; Marković, Z.; Marković, S.; Kolar-Anić, Lj.; Anal. Chim. Acta 2007, 582, 367.

18. Maksimović, J.; Kolar-Anić, Lj.; Anić, S.; Ribič, D.; Pejić, N.; J. Braz. Chem. Soc. 2011, 22, 38.

19. Jiménez-Prieto, R; Silva, M.; Pérez-Bendito, D.; Anal. Chem. 1995, 67, 729.

20. Jimenez-Prieto, R.; Silva, M.; Perez-Bendito, D.; Analyst 1998, 123, $1 \mathrm{R}$.

21. Gao, J.; Pakistan J. Biol. Sci. 2005, 8, 512.

22. Strizhak, P. E.; Didenko, O. Z.; Ivashchenko, T. S.; Anal. Chim. Acta 2001, 428, 15.

23. Gao, J.; Dai, H.; Yang, W.; Chen, H.; Lv, D.; Ren, J.; Wang, L.; Anal. Bioanal. Chem. 2006, 384, 1438.

24. Bray, W. C.; J. Am. Chem. Soc. 1921, 43, 1262.

25. Bray, W. C.; Liebhafsky, H. A.; J. Am. Chem. Soc. 1931, 53, 38.

26. Dushman, S.; J. Phys. Chem. 1904, 8, 453.

27. Gray, P.; Scott, S. In Chemical Oscillations and Instabilities: Nonlinear Chemical Kinetics; Oxford University Press: Oxford, 1990.

28. Yaraliev, Y. A.; Uspekhi Khimii 1982, 51, 990.

29. Milošević, M.; Pejić, N.; Čupić, Ž.; Anić, S.; Kolar-Anić, Lj.; Mater. Sci. Forum 2005, 494, 369.

30. Field, R. J.; Burger, M.; Oscillations and Traveling Waves in Chemical System; Wiley: New York, 1985.

31. Kolar-Anić, Lj.; Schmitz, G.; J. Chem. Faraday Trans. 1992, $88,2343$.

32. Schmitz, G.; Phys. Chem. Chem. Phys. 1999, 1, 1909.

33. Ševčík, P.; Adamičková, Lj.; Chem. Phys. Lett. 1997, $267,307$.

34. Pejić, N.; Maksimović, J.; Ribič, D.; Kolar-Anić, Lj.; Russ. J. Phys. Chem. 2009, 83, 1666.

35. Schmitz, G.; Phys. Chem. Chem. Phys. 2000, 2, 4041.

36. Furuichi, R.; Matsuzaki, I.; Simić, R.; Liebhafsky, A.; Inorg. Chem. 1972, 11, 952.

37. Schmitz, G.; J. Chim. Phys. 1987, 89, 7023.

38. Merkin, J. H.; Ševciková, H.; Phys. Chem. Chem. Phys. 1999, 1,91 .

39. International Conference on Harmonization (ICH); Harmonized Tripartite Guideline Validation of Analytical Procedures: Text and Methodology, Q2(R1), Geneva, 2005.

40. Bevington, P. R.; Robinson, D. K.; Data Reduction and Error Analysis for the Physical Sciences, $3^{\text {rd }}$ ed.; McGraw-Hill: New York, 2003.

41. Ševčík, P; Adamčiková L.; J. Phys. Chem. 1985, 89, 5178.

42. Burzyk, M.; Pulina, M.; Sajewicz, M.; Zjawiony, I.; Pol. Polar Res. 2006, 27, 327.

43. Kolar-Anić, Lj.; Mišljenović, Đ., Anić, S.; Nicolis, G.; React. Kinet. Catal. Lett. 1995, 54, 35. 
44. Agreda, J. A. B.; Field, R. J.; Lyons, N. J.; J. Phys. Chem. 2000, 104, 5269.

45. Liebhafsky, H. A.; Roe, G. M.; Int. J. Chem. Kin. 1979, 11, 693.

46. Gaspar, V.; Showalter, K.; J. Am. Chem. Soc. 1987, 109, 4869.

47. Bouillet, H.; Bull. Soc. Chim. 1901, 25, 251.

48. McCrudden, F. H.; Physiology and Patology of Uric Acid; Bibliolife LLC: Boston, 2008.
49. Ojo, J. F.; Otoikhian, A.; Olojo, R.; Simoyi, R. H.; J. Phys. Chem. A 2004, 108, 2457.

Submitted: October 18, 2011 Published online: July 12, 2012 